\title{
CONHECIMENTO TEÓRICO DE GRADUANDOS SOBRE PARADA CARDIORRESPIRATÓRIA NO SUPORTE BÁSICO DE VIDA
}

\author{
THEORETICAL KNOWLEDGE OF \\ UNDERGRADUATES ON CARDIORESPIRATORY \\ ARREST IN BASIC LIFE SUPPORT
}

\section{CONOCIMIENTOS TEÓRICOS DE LOS ESTUDIANTES UNIVERSITARIOS SOBRE LA PARADA CARDIORRESPIRATORIA EN SOPORTE VITAL BÁSICO}

\author{
Maria Gabriela Cordeiro Zago ${ }^{1}$ \\ Muriel Fernanda de Lima ${ }^{2}$ \\ Jean Carlos Ferreira ${ }^{3}$ \\ Jorseli Angela Henriques Coimbra ${ }^{4}$ \\ Lucas Vinícius de Lima ${ }^{5}$ \\ Carlos Alexandre Molena Fernandes ${ }^{6}$
}

Como citar este artigo: Zago MGC, Lima MF, Ferreira JC, Coimbra JAH, Lima LV, Fernandes CAM. Conhecimento teórico de graduandos sobre parada cardiorrespiratória no suporte básico de vida. Rev baiana enferm. 2021;35:e43704.

Objetivo: identificar o conhecimento teórico de graduandos de cursos que não são da saúde sobre parada cardiorrespiratória no suporte básico de vida. Método: pesquisa descritiva e exploratória de natureza quantitativa realizada com graduandos de universidade pública localizada no Noroeste do Paraná, em 2019. Para coleta dos dados, utilizou-se questionário, contendo caracterização do sujeito e dez questões referentes ao reconhecimento e atendimento de situações de parada cardiorrespiratória e reanimação cardiopulmonar. Os dados foram tabulados e analisados. Resultados: não se consideraram aptos para atendimento de evento de parada cardiorrespiratória 94,0\% dos participantes; 92,6\% não sabiam detectar essa condição; e 95,5\% não souberam qual conduta adotar. Conclusão: o conhecimento teórico de graduandos de cursos que não são da saúde sobre parada cardiorrespiratória foi insuficiente e é necessário treinamento para leigos em situações de emergência, para que o atendimento seja iniciado correta e imediatamente, sem postergar acionamento de serviço médico de emergência.

Descritores: Conhecimento. Parada Cardíaca. Reanimação Cardiopulmonar. Emergências.

Objective: to identify the theoretical knowledge of undergraduates of non-health courses about cardiorespiratory arrest on basic life support. Method: descriptive and exploratory research of quantitative nature carried out with graduates of public university located in the Northwest of Paraná, in 2019. For data collection, a questionnaire

\footnotetext{
Enfermeira. Mestre em Enfermagem. Maringá, Paraná, Brasil. gabriela-zago@hotmail.com. http://orcid.org/0000-0002-5426-3688.

Enfermeira. Doutora em Enfermagem. Docente da Universidade Federal do Mato Grosso do Sul, Campus Coxim. Coxim, Mato Grosso do Sul, Brasil. http://orcid. org/0000-000 I-9812-659X.

Enfermeiro. Pesquisador Independente. Paranavaí, Paraná, Brasil. http://orcid.org/0000-0002-06 I5-395 I.

4 Enfermeira. Doutora em Enfermagem. Docente da Universidade Estadual de Maringá. Maringá, Paraná, Brasil. http://orcid.org/0000-0002-93।4-9175.

Estudante de Enfermagem. Universidade Estadual de Maringá. Maringá, Paraná, Brasil. http://orcid.org/0000-0002-9582-9641.

6 Graduação em Educação Física. Doutor em Ciências Farmacêuticas. Docente da Universidade Estadual de Maringá. Maringá, Paraná, Brasil. http://orcid.org/00000002-40। 9-8379.
} 
was used, containing characterization of the subject and ten questions related to the recognition and attendance of situations of cardiorespiratory arrest and cardiopulmonary resuscitation. The data were tabulated and analyzed. Results: $94.0 \%$ of the participants were not considered fit for cardiorespiratory arrest event; $92.6 \%$ did not know bow to detect this condition; and 95.5\% did not know which conduct to adopt. Conclusion: the theoretical knowledge of undergraduates of non-bealth courses about cardiorespiratory arrest was insufficient and training is required for lay people in emergency situations, so that care is started correctly and immediately, without postponing emergency medical service activation.

Descriptors: Knowledge. Cardiac Arrest. Cardiopulmonary Resuscitation. Emergencies.

Objetivo: identificar los conocimientos teóricos de los estudiantes universitarios de cursos no sanitarios sobre la parada cardiorrespiratoria en soporte vital básico. Método: investigación descriptiva y exploratoria de carácter cuantitativo realizada con egresados de universidad pública ubicada en el Noroeste de Paraná, en 2019. Para la recolección de datos se utilizó un cuestionario, que contenía caracterización del sujeto y diez preguntas relacionadas con el reconocimiento y asistencia de situaciones de paro cardiorrespiratorio y reanimación cardiopulmonar. Los datos fueron tabulados y analizados. Resultados: el 94,0\% de los participantes no se consideraron aptos para el evento de paro cardiorrespiratorio; El 92,6\% no sabía cómo detectar esta afección; y el 95,5\% no sabía qué conducta adoptar. Conclusión: los conocimientos teóricos de los estudiantes universitarios de cursos no sanitarios sobre parada cardiorrespiratoria fueron insuficientes y se requiere capacitación para los laicos en situaciones de emergencia, de modo que la atención se inicie de manera correcta e inmediata, sin posponer la activación del servicio médico de emergencia.

Descriptores: Conocimiento. Paro Cardiaco. Resucitación Cardiopulmonar. Emergencias.

\section{Introdução}

O atendimento inicial de cenários de emergência é conhecido como Suporte Básico de Vida (SBV). Sua aplicação é indispensável para salvar vidas e prevenir sequelas, até que uma equipe especializada possa chegar ao local do acontecimento. O SBV inclui manobras de reanimação cardiopulmonar (RCP) nas vítimas em parada cardíaca, a desfibrilação por meio dos desfibriladores externos automáticos (DEA) e as manobras de desobstrução de vias aéreas devido a corpo estranho. O reconhecimento dessas situações e o atendimento básico imediato podem ser realizados por leigos, desde que devidamente informados e capacitados ${ }^{(1)}$.

A Parada Cardiorrespiratória (PCR) constitui-se numa condição de emergência, na qual o indivíduo apresenta interrupção súbita e inesperada do pulso arterial e da respiração, condições vitais ao ser humano ${ }^{(2)}$. A RCP baseia-se na realização de manobras específicas básicas, como descritas no SBV precoce, que consistem no reconhecimento e na tentativa de correção imediata da falência dos sistemas respiratório e/ou cardiovascular, até a chegada de uma equipe especializada ${ }^{(3)}$.
Estima-se que ocorrem em torno de $200 \mathrm{mil}$ PCRs ao ano no Brasil, sendo metade dos casos em ambiente pré-hospitalar, como residências, shopping centers, aeroportos, estádios e vias públicas, tornando-se um grave problema de saúde pública $^{(4)}$. Dentre as causas desse agravo, estão: traumas, choque e situações de insuficiência cardíaca ou infarto agudo do miocárdio ${ }^{(5)}$.

Os coeficientes de sobrevivência e de prognóstico de pacientes após PCR estão diretamente associados à agilidade com que é iniciada a busca pela reversão da PCR e à qualidade de sua realização ${ }^{(6)}$. A intervenção precoce na PCR, de forma segura e eficaz, pode até triplicar a sobrevida $^{(7)}$, pois cada minuto inferioriza as possibilidades de sobrevivência da vítima em cerca de $7 \%$ a $10 \%{ }^{(8-9)}$.

Nota-se uma grande necessidade de aprendizagem dos protocolos de primeiros socorros por leigos, devido ao conhecimento insuficiente apresentado por parte da população ${ }^{(10)}$, incluindo os acadêmicos.

Por conseguinte, o objetivo deste trabalho é identificar o conhecimento teórico de graduandos de cursos que não são da saúde sobre 
parada cardiorrespiratória no suporte básico de vida.

\section{Método}

Trata-se de uma pesquisa descritiva e exploratória de natureza quantitativa, realizada com acadêmicos dos diversos cursos de graduação ofertados por uma instituição de ensino superior pública, localizada na região Noroeste do estado do Paraná, no ano de 2019.

O local escolhido para a realização da pesquisa foi a Universidade Estadual do Paraná, campus Paranavaí, que oferece 12 cursos de graduação. Participaram da pesquisa os acadêmicos do primeiro ano dos cursos cujas matrizes curriculares não contêm componentes da área da saúde e noções de primeiros socorros: administração, ciências biológicas, ciências contábeis, direito, geografia, história, letras, matemática, pedagogia e serviço social. Foram excluídos da pesquisa os cursos de graduação em enfermagem e educação física e incluídos os cursos restantes do campus em questão. Não houve a realização de cálculo amostral, mas se levou em consideração o número de vagas ofertadas no vestibular de cada curso, chegando a uma média de 40 acadêmicos. Os cursos de graduação funcionam, conforme suas particularidades, nos períodos matutino, vespertino, noturno e integral.

Logo, os critérios de inclusão na pesquisa foram: ter idade igual e/ou superior a 18 anos e estar regularmente matriculado em um dos cursos de graduação escolhidos para a pesquisa. Como critério de exclusão, elencou-se não ter formação e/ou trabalhar na área da saúde.

Os acadêmicos foram convidados a participar da pesquisa, sendo-lhes explicado o objetivo e demais procedimentos metodológicos. Para os que se manifestaram a favor, foi apresentado o Termo de Consentimento Livre e Esclarecido (TCLE), que foi assinado em duas vias, ficando uma cópia com o participante e outra com o pesquisador, no qual estavam explicados todos os direitos do participante da pesquisa.

Para a coleta de dados, foi utilizado um questionário, contendo duas partes: a primeira, com uma breve caracterização do participante; a segunda, com perguntas formuladas de acordo com os objetivos da pesquisa. Para testagem e adequação, o roteiro foi submetido a uma banca de docentes atuantes na área de urgência e emergência. Posteriormente, foi aplicado a um grupo de acadêmicos não incluídos na pesquisa.

Como devolutiva de informação e disseminação do conhecimento na comunidade acadêmica, foi organizado um evento de treinamento de RCP nos intervalos das aulas do período noturno, durante 2 dias consecutivos. Uma equipe de pesquisa forneceu o apoio e transmitiu as informações essenciais sobre o SBV em cardiologia e orientações a respeito da maneira correta de realização das compressões torácicas. Os interessados foram convidados a realizar uma simulação de RCP em protótipos de reanimação Mini Anne, da Laerdal ${ }^{\circledR}$. Concomitantemente à simulação, os participantes foram orientados com informações pertinentes sobre a cadeia de sobrevida no SBV em cardiologia e acionamento dos serviços de urgência, em momento posterior à aplicação do questionário aos discentes de todos os cursos supracitados.

Os dados quantitativos coletados foram tabulados em planilha do Microsoft Office Excel 2010, analisados e apresentados em tabelas descritivas por meio de frequências.

A pesquisa foi desenvolvida após a autorização da instituição acadêmica e aprovação do Comitê de Ética em Pesquisa da Universidade Estadual do Paraná (UNESPAR), sob o Parecer $n^{\circ} 3.492 .539 / 2019$. Todos os preceitos éticos envolvendo pesquisas com seres humanos foram respeitados.

\section{Resultados}

A amostra foi constituída por 243 (90,7\%) indivíduos da Universidade Estadual do Paraná, campus Paranavaí. Todos responderam ao questionário com seus conhecimentos prévios sobre o assunto.

Observou-se predominância da faixa etária entre 18 e 20 anos e do sexo feminino, constituindo mais da metade dos participantes. Quanto 
à cor da pele, quase metade dos participantes declararam-se brancos e pardos. Quanto ao estado civil, o mais citado foi solteiro. A maioria dos participantes trabalhava e predominou a renda familiar de 3 a 4 salários-mínimos, seguida da renda de 2 salários-mínimos. Relativamente ao número de residentes no domicílio, obteve-se que a maioria residia com 3 a 4 pessoas na mesma habitação; a quase totalidade referiu não possuir filhos (Tabela 1).

Tabela 1 - Caracterização sociodemográfica dos graduandos dos cursos da Universidade Estadual do Paraná, campus Paranavaí. Paranavaí, Paraná, Brasil - 2019. (N=243)

\begin{tabular}{|c|c|c|}
\hline Variáveis & $\mathbf{n}$ & $\%$ \\
\hline \multicolumn{3}{|l|}{ Sexo } \\
\hline Feminino & 159 & 65,4 \\
\hline Masculino & 84 & 34,6 \\
\hline \multicolumn{3}{|l|}{ Faixa Etária } \\
\hline $18-20$ & 166 & 68,3 \\
\hline $21-30$ & 63 & 25,9 \\
\hline $31-40$ & 9 & 3,8 \\
\hline $40>$ & 5 & 2,0 \\
\hline \multicolumn{3}{|l|}{ Cor da pele } \\
\hline Branca & 120 & 49,3 \\
\hline Negra/preta & 12 & 4,9 \\
\hline Amarela & 7 & 2,9 \\
\hline Parda & 104 & 42,9 \\
\hline \multicolumn{3}{|l|}{ Estado civil } \\
\hline Solteiro & 219 & 90,1 \\
\hline Casado & 19 & 7,8 \\
\hline Amasiado & 4 & 1,7 \\
\hline Divorciado/separado & 1 & 0,4 \\
\hline \multicolumn{3}{|l|}{ Trabalha } \\
\hline Sim & 147 & 60,5 \\
\hline Não & 96 & 39,5 \\
\hline \multicolumn{3}{|l|}{ Renda familiar } \\
\hline Até 2 salários-mínimos & 94 & 38,7 \\
\hline De 3 a 4 salários-mínimos & 116 & 47,7 \\
\hline De 5 a 7 salários-mínimos & 28 & 11,5 \\
\hline De 8 a 10 salários-mínimos & 2 & 0,8 \\
\hline Acima de 10 salários-mínimos & 3 & 1,2 \\
\hline \multicolumn{3}{|l|}{ Número de residentes na casa } \\
\hline Mora sozinho & 4 & 1,7 \\
\hline 2 & 28 & 11,5 \\
\hline $3-4$ & 139 & 57,2 \\
\hline $5>$ & 72 & 29,6 \\
\hline \multicolumn{3}{|l|}{ Filhos } \\
\hline Não possui & 224 & 92,2 \\
\hline 1 & 8 & 3,3 \\
\hline 2 & 8 & 3,3 \\
\hline 3 ou mais & 3 & 1,2 \\
\hline
\end{tabular}

Fonte: Elaboração própria. 
Quanto às questões norteadoras, dispostas na Tabela 2, sobre participação em treinamento direcionado a situações de PCR, a quase totalidade dos participantes indicou não ter participado de treinamentos específicos para esta situação de emergência. Na questão seguinte, que abordou a obtenção de informações em PCR e como se realizava o atendimento, poucos deles responderam ter obtido informações em outros veículos de comunicação e a maior parte declarou que não teve acesso a outras fontes de informação. Para o questionamento sobre PCR presenciada em familiares ou alguém próximo, alguns afirmaram ter vivenciado esta cena e quase todos referiram nunca ter presenciado tal evento. $\mathrm{Na}$ última questão, que versava sobre o preparo dos indivíduos para atender uma situação de PCR, poucos responderam de maneira afirmativa e a quase totalidade respondeu não estar preparada para agir nessa situação.

Tabela 2 - Distribuição das respostas dos graduandos dos cursos da Universidade Estadual do Paraná, campus Paranavaí, sobre experiências prévias com situações envolvendo Parada Cardiorrespiratória. Paranavaí, Paraná, Brasil - 2019. (N=243)

\begin{tabular}{|c|c|c|}
\hline \multirow{2}{*}{ Questões } & \multicolumn{2}{|c|}{ Respostas (\%) } \\
\hline & Sim & Não \\
\hline $\begin{array}{l}\text { Já fez algum treinamento direcionado para atendimento de pessoas } \\
\text { em situação de Parada Cardiorrespiratória? }\end{array}$ & 9,24 & 90,76 \\
\hline $\begin{array}{l}\text { Já obteve informações sobre Parada Cardiorrespiratória e como se } \\
\text { realiza o atendimento por outros veículos de comunicação? }\end{array}$ & 18,07 & 81,93 \\
\hline $\begin{array}{l}\text { Já teve casos de Parada Cardiorrespiratória com um familiar ou } \\
\text { alguém próximo? }\end{array}$ & 19,68 & 80,32 \\
\hline $\begin{array}{l}\text { Você se sente preparado para socorrer uma pessoa em situação de } \\
\text { Parada Cardiorrespiratória? }\end{array}$ & 6,02 & 93,98 \\
\hline
\end{tabular}

Fonte: Elaboração própria.

Os dados apresentados na Tabela 3 expõem os percentuais de respostas corretas e incorretas dos graduandos acerca de Suporte Básico de Vida em Parada Cardíaca e Ressuscitação Cardiopulmonar. Pode-se perceber que os maiores percentuais encontram-se na coluna de respostas incorretas. Apenas na Questão E, relativamente à posição das mãos do socorrista na região torácica, o percentual de respostas corretas sobrepujou o de incorretas.

Tabela 3 - Distribuição das respostas dos graduandos dos cursos da Universidade Estadual do Paraná, campus Paranavaí sobre questões de Suporte Básico de Vida em Parada cardíaca e Ressuscitação cardiopulmonar. Paranavaí, Paraná, Brasil - 2019. (N=243)

\begin{tabular}{l|c|c}
\hline \multirow{2}{*}{ Questões } & \multicolumn{2}{|c}{ Respostas (\%) } \\
\cline { 2 - 3 } & Corretas & Incorretas \\
\hline A - Detecção da Parada Cardiorrespiratória & 7,4 & 92,6 \\
B - Conduta na Parada Cardiorrespiratória & 4,5 & 95,5 \\
C - Chamar ajuda (SAMU) & 49,8 & 50,2 \\
D - Número de compressões & 16,0 & 84,0 \\
E - Posição das mãos & 61,7 & 38,3 \\
F - Profundidade das compressões & 15,2 & 84,8 \\
G - Tempo de compressões & 12,4 & 87,7 \\
H - Posição da vítima & 46,9 & 53,1 \\
I - Uso do desfibrilador externo automático & 33,7 & 66,3 \\
J - Posição do socorrista & 22,6 & 77,8 \\
\hline
\end{tabular}

Fonte: Elaboração Própria. 


\section{Discussão}

Doenças relacionadas à circulação, a exemplo da PCR, afetam principalmente o coração e os vasos sanguíneos, constituindo um problema de saúde pública global. Na atualidade, constata-se que as ações do SBV devem ser iniciadas imediatamente, para a reversão da PCR e comprovação de um retorno com apresentação mínima de danos. Por isso, a participação do leigo no reconhecimento da PCR é importante ${ }^{(11)}$. Logo, é necessário que esse público consiga realizar tais cuidados, uma vez que é o primeiro a presenciar um mal súbito na maioria dos casos.

Socorristas leigos precisam seguir os critérios de reconhecimento da PCR, pedir ajuda, iniciar a RCP e aplicar a desfibrilação. Isto é, ter acesso público à desfibrilação (APD) até que um time de serviço médico de emergência (SME) com formação profissional assuma a responsabilidade e, em seguida, transporte o paciente para um tratamento definitivo de qualidade ${ }^{(12)}$.

Esta pesquisa localizou limitações teóricas e de habilidades práticas do público-alvo, diante de uma ocorrência de PCR, devido ao não entendimento e fundamentação do SBV. Uma pesquisa semelhante, realizada com discentes da Universidade Federal de Lavras (UFLA), identificou que o conhecimento prévio sobre o SBV era extremamente baixo ${ }^{(10)}$. Estudo que avaliou a entrega de treinamento teórico e prático da RCP a estudantes do ensino médio da rede pública de um município identificou, após realização de treinamento, melhora significativa, o que sustentou a percepção apresentada sobre a importância da inserção de assuntos relacionados à saúde nos componentes curriculares ${ }^{(13)}$.

Diante disso, pressupõe-se que o desconhecimento e a falta de preparo de grande parte da população acerca do assunto sejam o principal empecilho para salvar vidas. Segundo estudo realizado com o objetivo de compreender as razões pelas quais leigos não intervêm em casos de PCR, encontrou-se, como principais motivos: ausência de conhecimento sobre o assunto ou dificuldade de identificar uma parada cardíaca associado ao medo de agir da forma incorreta e causar prejuízos à vítima ${ }^{(14)}$.
Sobre o reconhecimento e a conduta assumida diante do cenário de PCR, nesta pesquisa, os resultados sinalizaram que a maior parte dos participantes não sabia identificar e agir perante o evento. À vista disso, os esforços educacionais devem ser direcionados para ajudar o público leigo a compreender que as pessoas vítimas de PCR podem ter inicialmente atividades semelhantes às crises ou respirações anormais e que todos os esforços devem ser feitos para minimizar os atrasos no início do cuidado ${ }^{(14)}$.

De acordo com as diretrizes de atendimento de RCP da American Heart Association (AHA), para adultos em Parada Cardiorrespiratória Extra Hospitalar (PCREH), socorristas leigos não treinados devem aplicar RCP somente com compressões torácicas com ou sem assistência de atendentes, pois são de fácil execução e podem ser facilmente orientadas por um profissional de emergência especializado ${ }^{(15-16)}$.

Com o início precoce das ações de SBV, tem-se conhecimento de mais chances de reversão de PCR e indícios de menos sequelas para o indivíduo ${ }^{(11)}$. No presente estudo, com relação ao número de compressões, uma pequena parcela dos graduandos assinalou corretamente "no mínimo 100"; responderam acerca da profundidade das compressões corretamente "pelo menos $5 \mathrm{~cm}$ " e uma quantidade menor de participantes soube responder o tempo correto de compressões.

Estudo $^{(17)}$ mostrou que vítimas que receberam as compressões torácicas precocemente tiveram uma taxa de sobrevida de 6,7\%. Logo, quanto mais rápido for o socorro, maiores são as chances de sucesso no retorno circulatório, pois, a cada minuto sem atendimento eficaz, perde-se a possibilidades de $7 \%$ a $10 \%$ de reanimação.

Neste estudo, observou-se que menos da metade sabia como posicionar a vítima para realizar RCP. No entanto, a maioria soube localizar o local para realização das compressões torácicas, sendo a questão com maior porcentagem de acertos. Dentre as principais justificativas dos leigos para não realizarem isoladamente a massagem cardíaca, incluem-se o desconhecimento do que fazer e/ou o medo de se contaminar por doenças infectocontagiosas ${ }^{(3)}$. 
Com a implantação do serviço pré-hospitalar móvel, previsto na Política Nacional de Atenção às Urgências (PNAU), assim como de suas centrais de regulação em municípios e regiões de todo o território brasileiro, verificou-se um importante avanço, tendo em vista que o quadro de morbimortalidade do Brasil relacionado às urgências diminuiu ${ }^{(18)}$.

Para o acionamento do serviço de emergência, nesta pesquisa, a maioria dos participantes não sabia acionar o SAMU, mencionando outro serviço de emergência. Contudo, ligar para um setor institucionalizado de saúde representa uma vantagem em relação àqueles que não ligariam para nenhum local em busca de socorro ${ }^{(1)}$.

O acionamento de ajuda, com solicitação de um DEA ${ }^{(9)}$, demonstra-se um preditor importante de sobrevida e qualidade de vida a longo prazo em pacientes acometidos por um evento de PCR fora do ambiente hospitalar ${ }^{(19)}$. Entretanto, mesmo nos dias de hoje, apesar de ser fundamental para o sucesso na reversão da PCR, são muitas as barreiras para o uso desse equipamento, principalmente devido à disponibilidade reduzida nos espaços públicos ${ }^{(20)}$.

De acordo com estudos populacionais, o APD, colocando DEA à disposição de leigos treinados no seu uso, tem o potencial de ser a intervenção que representa maior avanço no tratamento da PCR em fibrilação ventricular, desde o desenvolvimento da RCP, pois permite que as vítimas sejam desfibriladas dentro dos primeiros minutos de $\mathrm{PCR}^{(21)}$.

No presente estudo, quanto ao uso do DEA, um terço dos participantes apresentou conhecimento sobre sua utilidade, corroborando resultado de estudo realizado recentemente, no qual apenas 13,8\% dos participantes responderam corretamente acerca da funcionalidade desse equipamento $^{(22)}$.

O Brasil não possui um programa que aborde o assunto de forma definitiva, no entanto a Lei no 13.722 , de 4 de outubro de 2018, conhecida como Lei Lucas, torna obrigatória a capacitação em noções básicas de primeiros socorros de professores e funcionários de estabelecimentos de ensino públicos e privados de educação básica e de estabelecimentos de recreação infantil ${ }^{(23)}$. A predileção desse ambiente para a realização de treinamentos é embasada no fato de os alunos encontrarem-se em uma fase de grande motivação, na qual aprendem com maior rapidez e retêm habilidades com maior facilidade ${ }^{(18)}$. Não há concordância sobre a melhor idade para iniciar o treinamento de RCP. No entanto, crianças menores de nove anos de idade, apesar de não conseguirem realizar a habilidade com destreza, conseguem instruir adultos próximos ${ }^{(17)}$. Além disso, a reação positiva das crianças diante da aquisição de novos conhecimentos pode desencadear a propagação desse treinamento para suas famílias e amigos ${ }^{(24)}$. Com a inserção desse tema nos currículos escolares, espera-se que possa contribuir para treinamentos contínuos dirigidos a leigos ${ }^{(22)}$.

Atualmente, dentre as diversas metodologias existentes para disseminação de conhecimento, destaca-se a utilização de bonecos realísticos em treinamentos teórico-práticos, que é um método eficiente para a finalidade de expandir o conhecimento sobre RCP e para a qualidade dos movimentos $^{(25)}$.

Estes dados apontam que os conhecimentos de graduandos a respeito de SBV são reduzidos, o que torna fundamental a realização de treinamentos, para que se conte com a participação da população leiga no atendimento à PCR, proporcionando a redução do tempo entre a ocorrência e o início das intervenções. Assim, justifica-se a importância da educação da comunidade leiga na detecção precoce das emergências cardiovasculares $^{(10)}$. Não se pode deixar de considerar a possibilidade de o conhecimento perder-se com o passar do tempo, devido à falta de treinamentos. O treinamento em intervalos regulares é necessário para manter as habilidades, devido às atualizações das diretrizes da AHA, que são revisadas periodicamente ${ }^{(17)}$.

Este estudo apresenta algumas limitações que podem restringir a interpretação e generalização dos resultados, tendo em vista que refletem dados provenientes de um grupo e de uma realidade ímpares. Sugere-se que esta proposta 
seja utilizada em outros cenários, mas, principalmente, inserida na educação de leigos.

\section{Conclusão}

O estudo realizado permitiu concluir-se que o conhecimento teórico de graduandos de cursos que não são da saúde sobre parada cardiorrespiratória foi insuficiente, o que torna necessário treinamento para leigos em situações de emergência, para que o atendimento seja iniciado correta e imediatamente, sem postergar o acionamento de serviço médico de emergência.

Como visto, a população leiga detém conhecimento limitado a respeito de atendimento às vítimas de parada cardiorrespiratória, quanto à detecção e abordagem de uma vítima de PCR, acionamento do serviço de emergência, realização de compressões torácicas e posicionamento adequado da vítima em superfície rígida, além de número mínimo de compressões e tempo, profundidade e, posteriormente, utilização do DEA.

Nesta circunstância, constata-se que a educação é um instrumento importante para promoção de saúde e desenvolvimento de ações de prevenção de agravos. Por isso, é necessária a disseminação de informações que possam contribuir com a atuação de leigos em emergências pré-hospitalares.

\section{Colaborações:}

1 - concepção, projeto, análise e interpretação dos dados: Maria Gabriela Cordeiro Zago, Muriel Fernanda de Lima, Jean Carlos Ferreira, Lucas Vinícius de Lima e Carlos Alexandre Molena Fernandes;

2 - redação do artigo e revisão crítica relevante do conteúdo intelectual: Maria Gabriela Cordeiro Zago, Muriel Fernanda de Lima, Jean Carlos Ferreira e Jorseli Angela Henriques Coimbra;

3 - aprovação final da versão a ser publicada: Maria Gabriela Cordeiro Zago e Muriel Fernanda de Lima.

\section{Referências}

1. Chehuen Neto JA, Brum IV, Pereira DR, Santos LG, Moraes SL, Ferreira RE. Conhecimento e Interesse sobre Suporte Básico de Vida entre Leigos. Int J Cardiovasc Sci. 2016;29(6):443-52. DOI: $10.5935 / 2359-4802.20160064$

2. Barbosa JSL, Moraes-Filho IM, Pereira BA, Soares SR, Silva W, Santos OP. O conhecimento do profissional de enfermagem frente à parada cardiorrespiratória segundo as novas diretrizes e suas atualizações. Rev Cient Sena Aires [Internet]. 2018 [cited 2020 Dec 12];7(2):117-26. Available from: http://revistafacesa.senaaires.com.br/index. $\mathrm{php} / \mathrm{revisa} /$ article/view/311

3. Silva KR, Araújo SAST, Almeida WS, Pereira IVDS, Carvalho EAP, Abreu MN. Parada Cardiorrespiratória e o Suporte Básico de Vida no Ambiente Pré-Hospitalar: o Saber Acadêmico. Saúde (Santa Maria). 2017;43(1):53-9. DOI: https://doi.org/10.5902/2236583422160

4. Zandomenighi RC, Martin EAP. Análise epidemiológica dos atendimentos e parada cardiorrespiratória. Rev Enferm UFPE on-line. 2018;12(7):1912-22. DOI: https://doi.org/10.5205/ 1981-8963-v12i7a234593p1912-1922-2018

5. Aguiar JBN, Andrade EGS. Conhecimento da equipe de enfermagem sobre o protocolo de ressuscitação cardiorrespiratória no setor de emergência. Rev Inic Cient Ext [Internet]. 2018 [cited 2020 Dec 15];1(Esp 4):334-41. Available from: https://revistasfacesa.senaaires.com.br/ index.php/iniciacao-cientifica/article/view/111

6. Pettersen TR, Mårtensson J, Axelsson A, Jørgensen M, Strömberg A, Thompson DR, et al. European cardiovascular nurses' and allied professionals' knowledge and practical skills regarding cardiopulmonary resuscitation. Eur J Cardiovasc Nurs. 2018;17(4):336-44. DOI: $10.1177 / 1474515117745298$

7. Pinheiro DBS, Santos Júnior EB, Pinheiro LSB. Cardiorespiratory arrest: surveillance, prevention and care after PCR. J res: fundam care. Online. 2018;10(2):577-84. DOI: https://doi. org/10.9789/2175-5361.2018.v10i2.577-584

8. Ahmed SM, Garg R, Divatia JV, Rao SC, Mishra BB, Kalandoor MV, et al. Compressiononly life support (COLS) for cardiopulmonary resuscitation by layperson outside the hospital. Indian J Anaesth. 2017;61(11):867-73. DOI: 10. 4103/ija.IJA_636_17 
9. Bernoche C, Timerman S, Polastri TF, Giannetti NS, Siqueira AWS, Piscopo A, et al. Atualização da Diretriz de Ressuscitação Cardiopulmonar e Cuidados Cardiovasculares de Emergência da Sociedade Brasileira de Cardiologia - 2019. Arq Bras Cardiol. 2019;113(3): 449-663. DOI: http://dx.doi.org/10.5935/abc.2019 0203

10. Santos GAB, Gonçalves TSP, Aparecida F, Bruz FAF, Santos AC. Conhecimentos básicos sobre suporte básico de vida (SBV) em estudantes universitários. Rev Cient Eletrôn FACIMEDIT [Internet]. 2016 [cited 2020 Oct 10];5(1):42-53. Available from: https://pt.calameo.com/read/004 7553070cd604533825

11. Moraes TPR, Paiva EF. Enfermeiros da atenção primária em suporte básico de vida. Rev Ciênc Méd. 2017;26(1):9-18. DOI: 10.24220/2318-0897v26n1a3783

12. Bauer AC, Carvalho DFS, Franco GF, Costa JM, Taha Junior K. Suporte Básico de Vida: Atualização das Diretrizes da American Heart Association 2017. Rev Cient Multidisc Núcleo Conhec [Internet]. 2018 [cited 2021 Jan 8];4(4):83-98. Available from: https:// www.nucleodoconhecimento.com.br/saude/Suportebasico-de-vida

13. Costa LL, Botelho MHS, Cardoso ABR, Silva Martins D, Farias AF, Bueno CDF, et al. Cardiopulmonary Resuscitation: educational strategiesfor public network high school students in the municipality of Maraba-Para. Braz J Develop. 2020;6(2):9230-8. DOI: 10.34117/bjdv6 n2-292

14. Brady WJ, Mattu A, Slovis CM. Lay Responder Care for an Adult with Out-of-Hospital Cardiac Arrest. N Engl J Med. 2019;381(23):2242-51. DOI: 10.1056/NEJMra1802529

15. Nogueira MA, Maciel DO, Bernardes KC, Peres PVG, Oliveira VLG, Sá AMM. Teaching of basic life support in undergraduate nursing: an integrative review. Int J Current Res [Internet]. 2017 [cited 2020 Oct 10];9(8):56660-5. Available from: http://www.journalcra.com/sites/default/ files/25330.pdf.

16. Destaques das atualizações especificas das diretrizes de 2017 da American Heart Association para suporte básico de vida em pediatria e para adultos e qualidade da ressuscitação cardiopulmonar [Internet]. Feira de Santana; 2017 [cited 2020 Oct 20]. Available from: http://www. feiradesantana.ba.gov.br/samu192/protocolos/ DESTAQUE_AHA_2017.pdf

17. Carvalho LR, Ferreira RBS, Rios MA, Fonseca EOS, Guimarães CF. Factores asociados con el conocimiento de los laicos sobre el soporte vital básico. Rev Enferm Actual e Costa Rica. 2020;(38). DOI: 10.15517/revenf.v0i38.39087

18. Brasil. Ministério da Saúde. Portaria GM/MS $\mathrm{n}^{\circ} 1.864$, de 29 de setembro de 2003. Institui o componente pré-hospitalar móvel da Política Nacional de Atenção às Urgências, por intermédio da implantação do serviço de Atendimento Móvel de Urgência em municípios e regiões de todo o território brasileiro: SAMU-192 [Internet]. Brasília (DF); 2003 [cited 2020 Oct 15]. Available from: https://bvsms.saude.gov.br/bvs/saudelegis/ gm/2003/prt1864_29_09_2003.html

19. He D-X, Huang K-S, Yang YI, Jiang W, Yang N-L, Yan H. What is the Optimal Age for Students to Receive Cardiopulmonary Resuscitation Training? Prehosp Disaster Med. 2018;33(4):394-8. DOI: 10.1017/S1049023X18000 $47 \mathrm{X}$

20. Sun CLF, Demirtas D, Brooks SC, Morrison LJ, Chan CYT. Overcoming Spatial and Temporal Barriers to Public Access Defibrillators Via Optimization. J Am Coll Cardiol. 2016;68(8):83645. DOI: 10.1016/j.jacc.2016.03.609

21. Cartledge S, Saxton D, Finn J, Bray JE. Australia's awareness of cardiac arrest and rates of CPR training: results from the Heart Foundation's Heart Watch survey. BMJ Open. 2020;10(1):e:033722. DOI: 10.1136/bmjopen-2019-033722

22. Carvalho LR, Ferreira RBS, Rios MA, Fonseca EOS, Guimarães CF. Fatores associados ao conhecimento de pessoas leigas sobre suporte básico de vida. Enferm Actual Costa Rica. 2020;(38):163-78. DOI: http://dx.doi.org/10.15517/ revenf.v0i38.39087

23. Brasil. Ministério da Educação. Lei Lucas. Professores aprenderão noções básicas de primeiros socorros [Internet]. Brasília (DF); 2019 [cited 2020 Oct 8]. Available from: http://portal.mec. gov.br/ultimas-noticias/215-568057805/74791professores-aprenderao-nocoes-basicas-deprimeiros-socorros

24. Mpotos N, Iserbyt $P$. Children saving lives: Training towards CPR excellence levels in chest compression based on age and physical characteristics. Resuscitation. 2017;121:135-40. DOI: 10.1016/j.resuscitation.2017.10.024 
25. Schröder H, Henke A, Stieger L, Beckers S, Biermann $\mathrm{H}$, Rossant $\mathrm{R}$, et al. Influence of learning styles on the practical performance after the four-step basic life support training approach: An observational cohort study. PLoS
One. 2017;12(5):e0178210. DOI: 10.1371/journal. pone. 0178210

Recebido: 4 de março de 2021

Aprovado: 28 de junho de 2021

Publicado: 5 de outubro de 2021

A Revista Baiana de Enfermagem utiliza a Licença Creative Commons - Atribuição-NãoComercial 4.0 Internacional.

https://creativecommons.org/licenses/by-nc/4.0/

Este artigo é de acesso aberto distribuído sob os termos da Licença Creative Commons (CC BY-NC).

Esta licença permite que outros remixem, adaptem e criem a partir do seu trabalho para fins não comerciais. Embora os novos trabalhos tenham de lhe atribuir o devido crédito e não possam ser usados para fins comerciais, os usuários não têm de licenciar esses trabalhos derivados sob os mesmos termos. 